\title{
Clinical Approach for the Pneumomediastinum after Blunt Chest Trauma
}

\author{
Onder Kavurmaci, Tevfik Ilker Akcam*, Ali Ozdil, Ayse Gul Ergonul, Kutsal Turhan, \\ Alpaslan Cakan, Ufuk Cagirici
}

Department of Thoracic Surgery, School of Medicine, Ege University, Izmir, Turkey

Email: *tevfikilkerakcam@hotmail.com

How to cite this paper: Kavurmaci, O., Akcam, T.I., Ozdil, A., Ergonul, A.G., Turhan, K., Cakan, A. and Cagirici, U. (2017) Clinical Approach for the Pneumomediastinum after Blunt Chest Trauma. Open Journal of Thoracic Surgery, 7, 8-13. https://doi.org/10.4236/ojts.2017.71002

Received: January 16, 2017

Accepted: February 26, 2017

Published: March 1, 2017

Copyright ( $) 2017$ by authors and Scientific Research Publishing Inc. This work is licensed under the Creative Commons Attribution International License (CC BY 4.0).

http://creativecommons.org/licenses/by/4.0/

\section{(c) $)$ Op Open Access}

\begin{abstract}
Objective: Pneumomediastinum (PM) can be observed after blunt and penetrating chest trauma. Most of the patients with PM due to trauma can be managed conservatively. This study aimed to evaluate the cases with PM on thorax computed tomography (CT) after blunt chest trauma (BCT). Methods: Medical records of patients with PM due to BCT between January 2000 and December 2014 were reviewed retrospectively. Thorax CT was used to verify pneumomediastinum in all patients. Twenty-four patients which had different causes of PM (penetrating trauma, iatrogenic, spontaneous) were excluded from the study. Data of sixty-nine patients with the diagnosis of PM secondary to $\mathrm{BCT}$ and who were observed without any further procedure for the cause of PM, were evaluated retrospectively. Results: There were 59 male and 10 female patients with the mean age of $47.60 \pm 17.47$ years (range, 16 to 80 years). The most common cause of PM etiology was traffic accident with a rate of $38(55.06 \%)$ patients, followed by fall from height in 25 (36.24\%), compression in $3(4.35 \%)$ and drubbing in $3(4.35 \%)$ patients. There was a $12.46 \pm 6.42$ days (range, 6 to 28 days) mean duration of chest tube drainage which was performed for accompanying pathologies like pneumothorax and hemothorax. No complication was determined for short and long term follow-up of patients when all hospital records were analyzed in terms of complication. Conclusions: PM after BCT may be a marker of esophageal and tracheobronchial injury and invasive procedures like bronchoscopy and endoscopy can be needed for differential diagnosis. We evaluated 69 patients in good general status and no need for intensive care management with PM in this study and observed them without any further procedure. As a result of these findings we concluded that for the PM patients after BCT with uneventful clinical course, conservative treatment without any further procedure is a safe and sufficient method.
\end{abstract}




\section{Keywords}

Pneumomediastinum, Blunt Chest Trauma

\section{Introduction}

Pneumomediastinum (PM) is described as the presence of air in the mediastinum and can occur as a result of especial four different mechanisms. The first way is the passage of the air to the mediastinum through the natural potential spaces after facial and neck trauma. The second way is the transdiaphragmatic air passage due to abdominal organ perforation. The third way is the perforation of trachea, larynx or esophagus and lastly alveolar rupture secondary to increase of intrathoracic pressure and development of PM which is also known as "Marclin Effect" [1] [2].

In eighty percent of PM the etiologic factors are traumatic factors [3]. Blunt traumas compose $86 \%$ of traumatic factors whereas penetrating traumas or iatrogenic injuries during mechanical ventilation or endoscopic procedures compose $14 \%$ [4]. In this study, we aimed to evaluate the cases with blunt chest trauma followed up without any invasive diagnostic procedures like endoscopy or bronchoscopy after the improvement of PM on computed tomography.

\section{Material and Methods}

The patients who admitted to emergency room after blunt chest trauma and diagnosed as PM on computed tomography between January 2000 and December 2014 were reviewed retrospectively. The patients with missing data, inadequate results, follow-up information and underwent urgent operation or followed up in intensive care unit because of multi-system injury were excluded from study. The study included 69 patients who were followed up in thoracic surgery department with good and stable clinical status. All patients gave written informed consent. There was no radiological evidence of intra-abdominal, tracheo-bronchial or esophageal injury on tomographic imagination. Biochemical, radiological (chest X-ray, tomography), arterial blood gas, cardiac enzyme examinations, electrocardiogram and echocardiography of all patients were investigated. The patients were consulted about their accompanying injuries with the related clinics. If tube thoracostomy was performed due to pneumo and/or hemothorax, it was followed up until the end of air leak or hemorrhagic drainage under $100 \mathrm{cc}$ per day. The feeding of patients was started gradually and controlled with the findings of physical, biochemical and radiological examinations. Nasal oxygen inhalation ( $2-4 \mathrm{l} / \mathrm{min})$ was performed to all of the patients in order to accelerate the resorption of mediastinal emphysema. The patients were discharged after the complete resorption of PM which was proved radiologically and followed up by periodical outpatient controls. 


\section{Results}

The mean age of the patients (59 males, 10 females) was $47.60 \pm 17.47$ years (range, 16 to 80 years). The etiologic factors of blunt chest trauma were; traffic accident in $38(55.07 \%)$, fall from height in $10(14.49 \%)$, compression in 3 $(4.35 \%)$ and drub in $3(4.35 \%)$ patients (Figure 1). In 64 (92.7\%) patients pneumothorax was detected additional to the PM and 15 (21.73\%) of the pneumothorax were bilateral. The second common co-existing pathology was rib fracture. Rib fracture was observed in 59 (85.5\%) patients. More than three rib fractures were detected in $48(69.56 \%)$ and three or less fractures were detected in $11(15.94 \%)$ patients. The other co-existing morbidities were subcutaneous emphysema in $57(82.6 \%)$, hemothorax in 49 (71.0\%), bone fractures except rib fractures in 47 (68.1\%), intracranial hemorrhage in $5(7.2 \%)$ and intraabdominal organ injury in $5(7.2 \%)$ patients (Table 1$)$.

Forty-five tube thoracostomies were performed to 39 (56.53\%) patients. Basal and apical tube thoracostomies were performed to one patient and bilateral tube thoracostomies were performed to $5(7.24 \%)$ patients. Cutaneous and subcutaneous incisions were performed to 4 patients for subcutaneous emphysema. In 5 patients no other approach had been required except thoracentesis. The mean of hospital stay of patients underwent tube thoracostomy was $12.46 \pm 6.42$ days (range 6 to 28 days) and the mean of hospital stay of whole patients was $9.12 \pm$ 7.02 days (range 3 to 39 days). The patients were followed up in outpatient clinic at one week and one month of externation. Any complications like expansion failure, recurrence of PM or mediastinitis were not observed.

Table 1. Patients' demographic data.

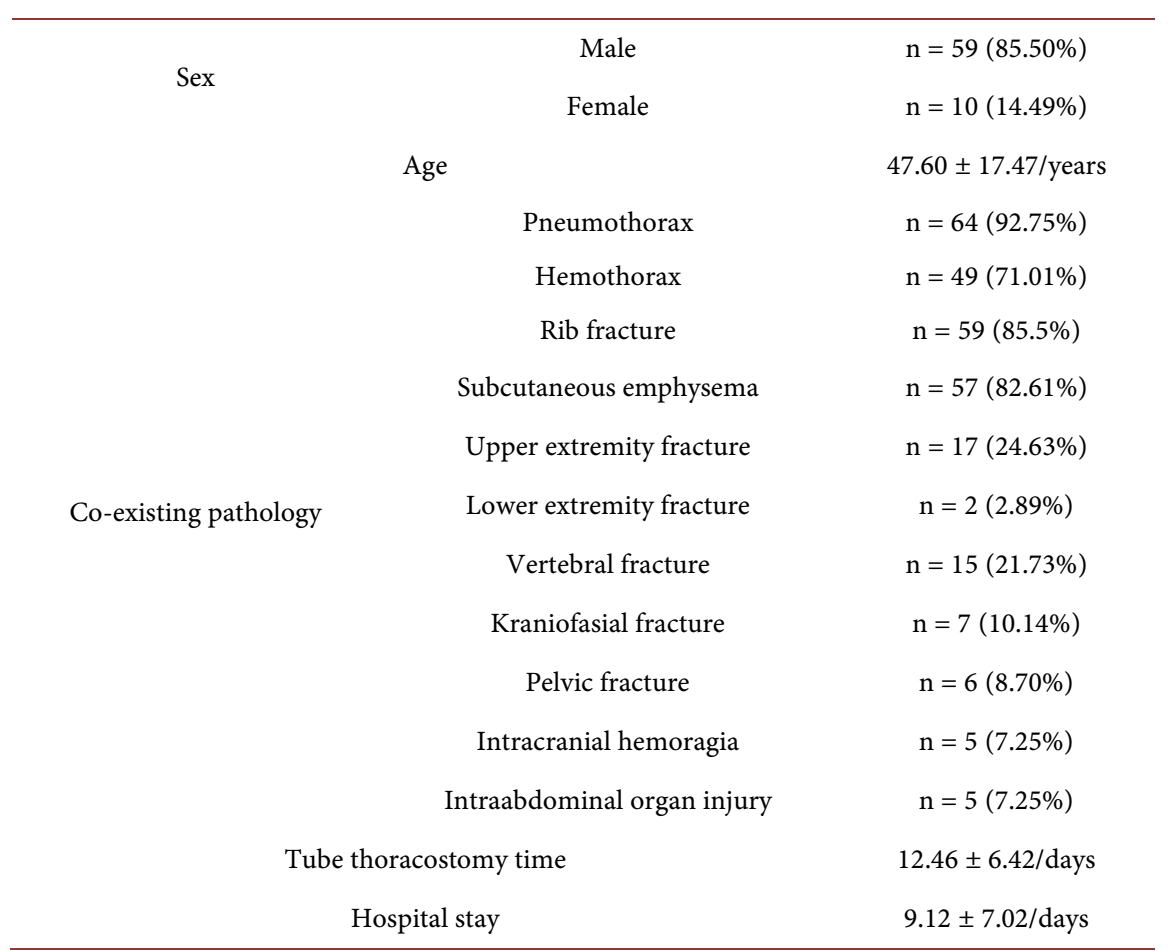

$\mathrm{n}=$ patient number. 


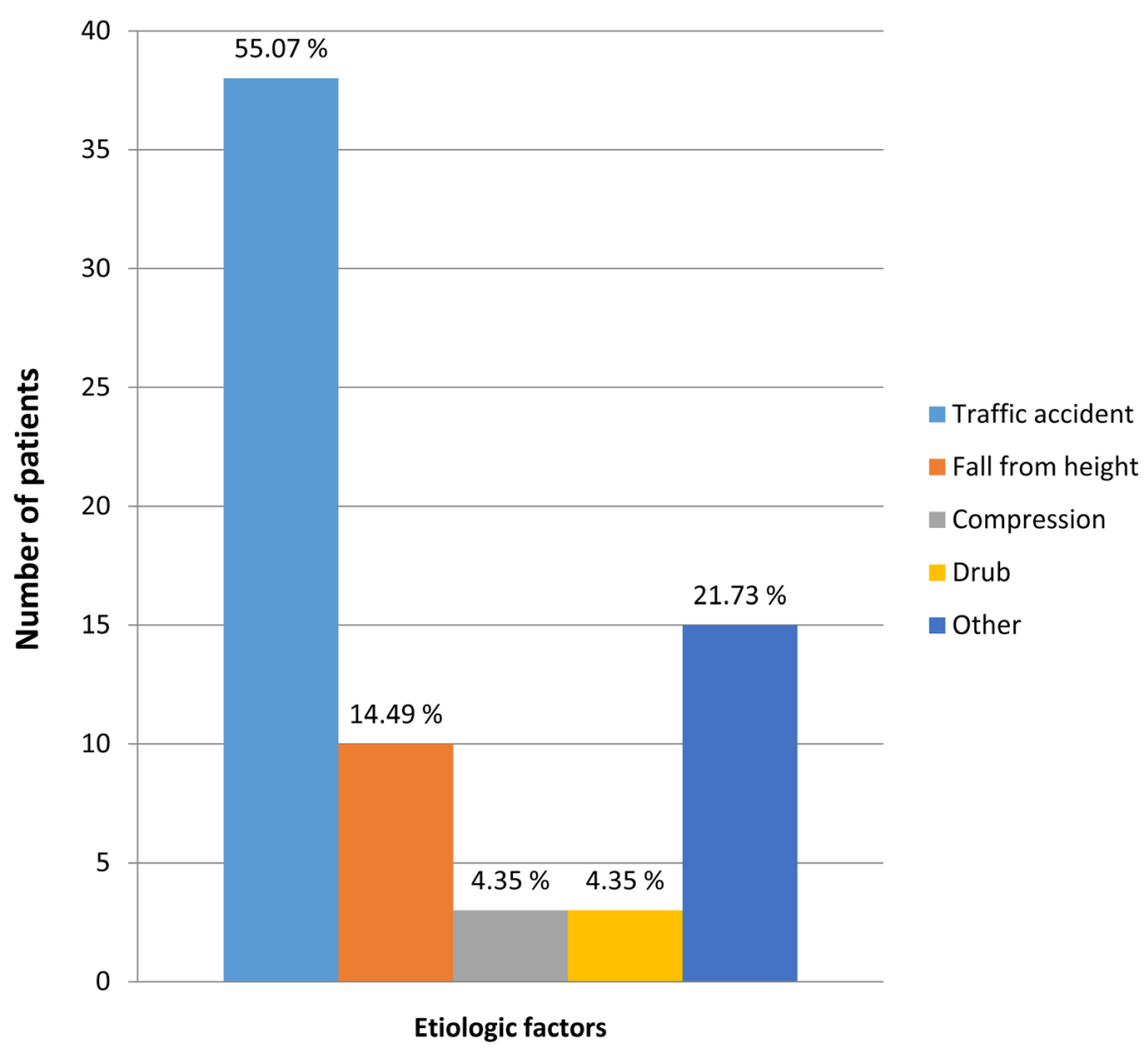

Figure 1. Patients' etiology of trauma.

\section{Discussion}

Traumatic PM is a rare pathology that can be observed after neck, thorax or abdominal trauma but it can be mortal due to relation with the injuries of tracheobronchial tree, esophagus or vascular elements [5]. Because of this reason the diagnosis of these possible underlying morbidities is one of the most important anxieties in the treatment of PM [6]. In a study including 32 pediatric patients with PM after blunt trauma, patients with isolated PM and stable clinical findings were followed up only with radiological examination without any invasive procedure and complication secondary to tracheobronchial injury was observed only in one patient [7]. It is reported that further invasive approaches were needless for the PM patients without the radiological and clinical findings of other system injuries, in the study grouping the PM was isolated and complicated to investigate the time of invasive procedures [8]. In another study defining the PM that only had been detected on thorax CT and not been seen on chest $\mathrm{X}$-ray without any clinical findings as "occult PM", it was offered observation of these patients without any invasive procedures [9]. Kaneki and colleagues reported that $30 \%$ of PM was misdiagnosed if the patients had been evaluated only by chest X-ray and mentioned the importance of thorax CT for the diagnosis of PM, in their study including 33 spontaneous PM patients [10]. Chouliaras and coworkers investigated the incidence of airway and digestive system injuries in blunt chest and neck trauma patients with PM and they observed 258 PM in 9946 patients. They reported that only 21 of 258 PM patients required further 
invasive procedures like bronchoscopy, esophagoscopy or esophagogram and lesion causing air leak was detected in only 4 patients. These lesions were tracheobronchial injury in 3 patients seen on thorax CT and esophageal injury in 1 patient shown by esophagogram. Two patients with tracheobronchial injury underwent surgical treatment and the other ones had been treated by medical treatment. The mortality was $10.9 \%$ in all of the patients [11].

Similar studies were reported in the literature for spontaneous PM also. Caceres and colleagues [12] evaluated 28 patients with spontaneous PM in their 12 years' experience and they mentioned that they had not detected any tracheoesophageal injury in these patients by performance of 16 esophagogram, 3 esophagoscopy and 1 bronchoscopy. In the study by Macia and coworkers, 41 patients with spontaneous PM were diagnosed on chest X-ray and CT, contrastenhanced swallow CT or bronchoscopy were performed in certain cases who had been suspected for esophageal or tracheobronchial injury. They did not report any additional radiological finding on thorax $\mathrm{CT}$ of 7 patients and contrast-enhanced swallow CT of 8 patients. They mentioned that they had performed bronchoscopy to one patient and no pathology was observed. The mean hospital stay of the patients who were observed with rest, analgesia and oxygen inhalation was reported as 5 days without any morbidity and mortality [13].

In our study, all of the PM patients were diagnosed with thorax CT and any tracheobronchial or esophageal injury was not detected on CT. We accept that the further endoscopic evaluation is needful (essential, obligatory) for the patients with the findings of tracheobronchial or esophageal injury on CT. Nevertheless we think that the observation without any further invasive procedures is enough for the PM patients without any additional finding on thorax CT. Limitations for our study were the exclusion of the patients undergone urgent surgery and follow-up in intensive care unit and also the lack of number of patients due to a single center based data. These results can be promoted by larger number of patients and multi-center based studies.

As a result, by the developing technology and increasing precision of screening methods we support that bronchoscopy and endoscopy will be less necessary for the establishing coexisting injuries in PM patients.

\section{Conflicts of Interest}

Authors declare no conflicts of interest with respect to the authorship and/or publication of this article.

\section{Funding}

The authors received no financial support for the research and/or authorship of this article.

The procedures followed were in accordance with the ethical standards of the responsible committee on human experimentation (institutional and national) and with the Helsinki Declaration of 1975, as revised in 2000 and 2008. 


\section{References}

[1] Macklin, C. (1939) Transport of Air along Sheaths of Pulmonic Blood Vessels from Alveoli to Mediastinum: Clinical Implication. Archives of Internal Medicine, 64, 913-926. https://doi.org/10.1001/archinte.1939.00190050019003

[2] Wintermark, M. and Schnyder, P. (2001) The Macklin Effect: A Frequent Etiology for Pneumomediastinum in Severe Blunt Chest Trauma. Chest, 120, 543-547. https://doi.org/10.1378/chest.120.2.543

[3] Banki, F., Estrera, A.L., Harrison, R.G., et al. (2013) Pneumomediastinum: Etiology and a Guide to Diagnosis and Treatment. The American Journal of Surgery, 206, 1001-1006. https://doi.org/10.1016/j.amjsurg.2013.08.009

[4] Sahni, S., Verma, S., Grullon, J., Esquire, A., Patel, P., et al. (2013) Spontaneous Pneumomediastinum: Time for Consensus. North American Journal of Medical Sciences, 5, 460-464. https://doi.org/10.4103/1947-2714.117296

[5] Bejvan, S.M. and Godwin, J.D. (1996) Pneumomediastinum: Old Signs and New Signs. American Journal of Roentgenology, 166, 1041-1048. https://doi.org/10.2214/ajr.166.5.8615238

[6] Karny-Jones, R., Wood, D.E. and Jurkovich, G.J. (2008) Esophagus, Trachea, and Bronchus in Trauma. In: Feliciano, D.V., Mattox, K.L. and Moore, E.E., Eds., Trauma, 6th Edition, MacGraw-Hill, New York, 553-567.

[7] Neal, M.D., Sippey, M., Gaines, B.A. and Hackam, D.J. (2009) Presence of Pneumomediastinum after Blunt Trauma in Children: What Does It Really Mean? Journal of Pediatric Surgery, 44, 1322-1327. https://doi.org/10.1016/j.jpedsurg.2009.02.069

[8] Pryor, S.D. and Lee, L.K. (2011) Clinical Outcomes and Diagnostic Imaging of Pediatric Patients with Pneumomediastinum Secondary to Blunt Trauma to the Chest. Journal of Trauma, 71, 904-908. https://doi.org/10.1097/TA.0b013e31820edfbe

[9] Rezende-Neto, J.B., Hoffman, J.A.L., Mahroos, M., Tien, H., Hsee, L.C., et al. (2010) Occult Pneumomediastinum in Blunt Chest Trauma: Clinical Significance. Injury, 41, 40-43. https://doi.org/10.1016/j.injury.2009.06.161

[10] Kaneki, T., Kubo, K., Kawashima, A., Koizumi, T., Sekiguchi, M., et al. (2000) Spontaneous Pneumomediastinum in 33 Patients: Yield of Chest Computed Tomograph for the Diagnosis of Themild Type. Respiration, 67, 408-411.

https://doi.org/10.1159/000029539

[11] Chouliaras, K., Bench, E., Talving, P., Strumwasser, A., Benjamin, E., et al. (2015) Pneumomediastinum Following Blunt Trauma: Worth an Exhaustive Workup? Journal of Trauma and Acute Care Surgery, 79, 188-192. https://doi.org/10.1097/TA.0000000000000714

[12] Caceres, M., Ali, S.Z., Braud, R., Weiman, D. and Garrett, J.H.E. (2008) Spontaneous Pneumomediastinum: A Comparative Study and Review of the Literature. The Annals of Thoracic Surgery, 86, 962-966. https://doi.org/10.1016/j.athoracsur.2008.04.067

[13] Maciaa, I., Moyab, J., Ramosb, R., Moreraa, R., Escobara, I., et al. (2007) Spontaneous Pneumomediastinum: 41 Cases. European Journal of Cardio-Thoracic Surgery, 31, 1110-1114. https://doi.org/10.1016/j.ejcts.2007.03.008 
Submit or recommend next manuscript to SCIRP and we will provide best service for you:

Accepting pre-submission inquiries through Email, Facebook, LinkedIn, Twitter, etc. A wide selection of journals (inclusive of 9 subjects, more than 200 journals)

Providing 24-hour high-quality service

User-friendly online submission system

Fair and swift peer-review system

Efficient typesetting and proofreading procedure

Display of the result of downloads and visits, as well as the number of cited articles Maximum dissemination of your research work

Submit your manuscript at: http://papersubmission.scirp.org/

Or contact ojts@scirp.org 